\title{
NATUREZA, TRABALHO E TERRA NA AMAZÔNIA NA VIRADA DO SÉCULO
}

\section{ARTIGO ORIGINAL}

MELO, Sheila de Souza Corrêa de ${ }^{1}$

OLIVEIRA, Ana Vieira de ${ }^{2}$

VASCONCELOS, Marcelo Augusto Machado ${ }^{3}$

MELO, Sheila de Souza Corrêa de. OLIVEIRA, Ana Vieira de. VASCONCELOS, Marcelo Augusto Machado. Natureza, trabalho e terra na Amazônia na virada do século. Revista Científica Multidisciplinar Núcleo do Conhecimento. Ano 05, Ed. 05, Vol. 12, pp. 146-154. Maio de 2020. ISSN: 2448-0959, Link de acesso: https://www.nucleodoconhecimento.com.br/historia/terra-na-amazonia

\section{RESUMO}

Ao longo do processo de urbanização, a história dos modelos produtivos na Amazônia tem sido caracterizada pela proeminência da atividade extrativa. Esse panorama foi intensificado entre o final do século XIX e primeira metade do século XX a partir da importância que a extração de látex para produção de borracha teve na economia global. A partir do látex e do seringal, constitui-se mais do que uma economia amazônica, mas uma sociedade. Este artigo busca reconstruir alguns aspectos da relação entre natureza, trabalho e sociedade na Amazônia a partir desse momento de transição e dos efeitos da economia e as relações entre grupos sociais na organização de uma sociedade gomífera. Metodologicamente o trabalho parte de técnicas da

\footnotetext{
${ }^{1}$ Mestre em Propriedade Intelectual e Inovação, pós graduanda em História Agrária da Amazônia Contemporânea na UFPA, Bacharel em Direito.

${ }^{2}$ Mestranda em História pela UFPA e especialista em História.

${ }^{3}$ Doutor em Ciências Agrárias, Mestre em Agriculturas Amazônicas, Agrônomo.
} 
história, utilizando-se particularmente da análise documental e da pesquisa bibliográfica. Os resultados sugerem um processo de reordenamento nos modos de organização social a partir do modo como grupos sociais diferentes beneficiavam-se da venda da borracha. O seringal, a colocação, o barracão e a cidade constituem-se assim como metáforas e como realidades empíricas para compreensão das formas de desigualdade no acesso à terra e nas relações de trabalho das pessoas na Amazônia que podem ser vislumbradas ainda hoje, apesar das transformações recentes.

Palavras-Chave: Sociedade e natureza, economia gomífera, seringal, Amazônia, história contemporânea.

\section{INTRODUÇÃO}

O exercício historiográfico é um investimento na produção narrativa de eventos, trajetórias e fenômenos a partir de um determinado conjunto de materiais. Se tomarmos essa afirmação como plausível, então é possível supor também que as histórias são elaborações parciais e compósitas, ou seja, se configuram como múltiplas e repletas de camadas de modo que projetos distintos podem ser coligados na composição de histórias maiores, articuladas, e que abrigam um maior volume de perspectivas, objetos de indagação e elementos em reflexão.

Sendo a produção da história um exercício narrativo estabelecido a partir de inúmeras perspectivas, personagens ou objetos, etc., então talvez seja também possível considerar que cada uma dessas formas e locais de produção narrativas têm potencialidades, efeitos e estéticas próprias que podem ser colocadas em diálogo em um exercício de composição multivocal ou multirreferencial.

Nesses termos, produzir uma narrativa dos processos de transformação social a partir do vestiário, da moeda, da literatura, da arquitetura dos espaços, enfim, qualquer que seja o objeto ou cenário, constitui-se como um investimento fragmentado na tentativa de construção de quadros suficientemente detalhados que se somam e conjugam a outros maiores. Essa hipótese é fundamental para o tipo de exercício sobre o qual 
este breve ensaio se dedica a pensar: os processos de transformação produzidos a partir da economia da borracha, tomando como ponto de vista para elaboração narrativa as relações entre trabalho e uso da terra na Amazônia.

A questão então é: como os objetos, lugares, registros, vozes e fenômenos que os historiadores elegem para construção de suas interpretações participam das análises de uma situação ou momento no tempo e no espaço? A partir de quais perspectivas tem sido construída a história da Amazônia e de que modo pensar a relação entre trabalho e uso da terra pode ser uma forma de perceber as idiossincrasias, complexidades e universos de relações em tensão e disputa que configuram o espaço histórico amazônico na transição entre o século XIX para o século XX? Esse curto ensaio não tem como propósito responder essas perguntas, mas antes, pensar a partir delas. Em outras palavras, o exercício aqui é a partir da seleção de um momento específico construir algumas hipóteses sobre a narrativa histórica da construção da Amazônia. O propósito não é realista, no sentido de construir uma análise que toma como suposto uma noção de "é assim", mas a elaboração alguns insights de pretensão demonstrativa e exemplar, ao modo de um "pode ter sido" ou "poderia ser", recorrendo assim a uma aproximação entre narrativa e exercício especulativo pouco habitual na produção historiográfica.

\section{HISTÓRIAS PARTIDAS, NARRATIVAS ELÁSTICAS}

A historiografia sobre a formação do Brasil ainda é marcada por lacunas no que diz respeito à conformação do espaço social e político do que geopoliticamente hoje é marcado como "região norte", e mais ainda no que diz respeito à Amazônia brasileira. A despeito das complexidades ambientais e mesmo geopolíticas de um espaço que mescla e confunde a geografia supranacional dos ecossistemas à política espacial dos territórios, a ocupação humana na Amazônia precede a própria possibilidade de documentação sobre o território. Ou seja, se os registros arqueológicos sugerem que a presença humana na forma de sociedades autóctones é de mais de 12 mil anos, o volume mais significativo de informações escritas sobre a região tem poucos séculos. Some-se a isso o fato desse registro ser produtor da empreitada colonial através do Estado na forma das campanhas de povoamento e controle das fronteiras, seja 
através da Igreja através das missões de 'amansamento' dos 'índios bravos' (GOMES, 1991).

Apesar dessa intensa ocupação nativa no período prévio à colonização e ao intenso fluxo de missionários de ordens diversas nas primeiras metades do século, é ainda recorrente que a história local só se esboce a partir de narrativas que se debruçam sobre a conformação modernista e de progresso do desenho urbano a partir da virada do século XIX para o século XX, como indicam Lacerda e Vieira (2002). Um elemento importante para tensionar essa perspectiva de uma arquitetura amazônica que ignora a engenharia das relações interétnicas e de relação com a terra e o trabalho pode ser traçada a partir da ascensão da borracha no final do século XIX.

Se como sugeriu Gomes (2002), o Brasil é uma justaposição de ideias paradoxais entre acumulação e projetos de desenvolvimento, então é preciso localizar a criação de um imaginário sobre a Amazônia também na formulação desse quadro problemático. Acompanhando os argumentos do autor,

Não podemos esquecer que, na origem, a Amazônia não pertencia ao Brasil. Na verdade, os portugueses tinham duas colônias na América do Sul, uma descoberta por Cabral em 1500, governada pelo vice-rei do Brasil, a outra, o Grão-Pará e Rio Negro, descoberta por Vicente lañes Pinzon em 1498, logo após a terceira viagem de Colombo à América, quando batizou o rio Amazonas de mar Dulce, mas efetivamente ocupada pelos portugueses a partir de 1630. Esses dois Estados se desenvolveram distintamente até 1823, data em que o Império do Brasil começou a anexar o seu vizinho. A violência era naquela altura a única via possível, tão diferentes eram as estratégias, a cultura e a economia dessas duas colônias. A Amazônia então não era uma fronteira: este é um conceito que foi inventando pelo Império e retomado pela República.

No Grão-Pará e Rio Negro, a economia era fundada na produção manufaturada, a partir das transformações do látex. Era uma indústria florescente, produzindo objetos de fama mundial, como sapatos e 
galochas, capas impermeáveis, molas e instrumentos cirúrgicos, destinados à exportação ou ao consumo interno (GOMES, 2002, p.31-2)

A economia gomífera ocupa uma posição dramática na história da configuração das relações econômicas, ecológicas e sociais no contexto amazônico. Isso porque no período que marca o fim do século XIX e o começo do século XX o látex e a borracha passam a ocupar uma posição central no contexto de trocas e produção industrial ocidental. Sendo a Amazônia um contexto de excelência para produção de matéria prima para a indústria, encenou-se no espaço social a aproximação e tensão entre diversos contingentes populacionais interessados em extrair da demanda do mercado formas de rentabilização e ganho, mesmo que para isso constituindo cadeias de exploração e controle sobre outras formas de vida, humanas e não humanas.

A inserção da borracha e a localização da Amazônia como um território favorável na produção da matéria prima ocupou uma posição fundamental no ordenamento do espaço amazônico contemporâneo, mesmo que, como sugeriu Barbara Weinstein (2002, p.268), a borracha já ocupasse um lugar na economia local das relações entre natureza e sociedade. De todo modo, a demanda mundial pela borracha entre o fim do século XIX e começo do século XX teve um papel importante e participou da estruturação e integração da região ao contexto nacional, e em alguma medida, ao internacional. Mais que isso, no contexto local a borracha constituiu também uma linguagem para as relações ali travadas: economia gomífera, sociedade do seringal, império da borracha são expressões que informam sobre a produtividade da economia extrativa e o modo com a relação entre natureza, terra e trabalho foi um motor de inteligibilidade para relações que posicionavam e valorizavam de maneiras distintas ideias relativas a gênero, nação, etnicidade, raça e classe.

Se considerarmos no contexto de uma filosofia política no trabalho como a elaboração, ou, melhor dizendo, transformação (transformação da capacidade produtiva em mercadoria, da experiência em narrativa, de matéria prima em produtos, etc) então é preciso considerar que o trabalho é uma forma de mediação entre a atividade material do uso da terra, com a atividade simbólica de valoração e hierarquização das existências e sentidos relacionados a esse espaço. Ou, de modo mais simples, o 
trabalho é a atividade principal de produção de sentido para a ação no mundo, e como determinados modos de agir são classificados, desprezados ou valorizados.

A relação com a terra produzida a partir da expansão da demanda pela goma utilizada na produção industrial de borracha pode ser pensada como um intenso catalizador de posições sociais a partir do extrativismo. Esse processo ordenou o espaço social, imprimindo na paisagem uma geografia modernista como aquela sinalizada por Lacerda e Vieira (2002), mas também imprimiu no contexto amazônico um léxico de relações que possivelmente se pudesse dizer em estado embrionário. Trata-se de pensar o barracão como um espaço de produção das relações amazônicas sob uma égide semelhante à utilizada por Gilberto Freyre ao justapor a Casa Grande e a Senzala como pontos de observação para a construção de uma sociedade fundada no patriarcado e na desigualdade racial.

Imagine-se o barracão como um espaço de teatralizado de encontro entre o produtor de borracha, o regatão, o dono da terra e o industrial. É no barracão que são expostas as assimetrias na relação entre os donos dos seringais e os extratores da seringa tendo como mediador o regatão, personagem que flutua e circula entre múltiplos regimes de exploração e de inscrição de desigualdades. Retomando Gomes,

Os proprietários extrativistas, entre eles os seringalistas, raramente se preocupavam com a terra. Eles controlavam a produção extrativa, financiavam a safra. Não eram exatamente senhores da terra, ou fazendeiros, mas apenas "dominadores" das áreas de matérias-primas como a castanha, a piaçava, madeira, a batata, a sorva e a borracha. Era, por certo, uma classe com características rurais no trato das relações de trabalho, mas a sua criatividade estava na capacidade de dinamizar a produção extrativa. Essa classe estabeleceu o controle da terra, abrangendo grandes áreas produtivas. O seu controle dos meios de produção limitava-se, basicamente, ao controle das áreas extrativas, já que no relacionamento com a natureza o proprietário extrativista não avançava o seu controle, não havia a preocupação do cultivo, da 
pesquisa, e a mão-de-obra era apenas considerada força de trabalho. (GOMES, 2002, p.34).

A instauração de uma força de trabalho apta para a borracha foi em muitos sentidos uma própria reelaboração modernista das relações coloniais. Se como advertia Barbara Weinstein (2002), a despeito da crescente demanda global pela matéria prima havia alguma resistência por parte de elites locais em situar a borracha como principal matéria prima da economia local, os lugares sociais de "caboclo", muitas vezes sinônimo para o indígena extrator, senhor de barracão bem como mediadores já estavam postos e em atividade. Se a relação entre sociedade, civilização e modernidade não é sempre pacífica, tampouco favorável ao bem viver, então é preciso deduzir dessa amálgama complexa de relações e espaços de exploração os sentidos e as possibilidades de existência que viabilizaram a produção de uma sociedade, economia ou império que se acabou sedimentando a centralidade do extrativismo naquele universo.

Aproximando o léxico da filósofa Judith Butler (2011), a elasticidade entre regimes de controle e interesses transnacionais na demanda por matéria prima atuou de modo a constituir uma justaposição dramática entre possibilidades de vida marcadas por um lado pela precariedade, e por outro pelo privilégio. Mais que uma aproximação entre existências precárias e mecanismos de assujeitamento, como mostrado na experiência de Mariana Pantoja (2008) sobre a trajetória de uma família na Reserva Extrativista do Alto Juruá, as relações instauradas pela borracha aproximaram um intenso fluxo de capital que aproximava fronteiras nacionais, ou como notou Bárbara Weinstein,

[h]avia uma tentativa séria de manter um 'corpo de trabalhadores' composto de homens não brancos e sem emprego fixo, abrangendo os habitantes empregados na 'coleta da seringa'. Evidentemente o caboclo que podia se sustentar coletando látex durante alguns meses do ano não estava disposto a trabalhar em troca de um ordenado diminuto nas fazendas das famílias tradicionais da região. E mais do que isso: a expansão do comércio da borracha criaria condições para uma presença 
maior de capital estrangeiro na região, uma potencialidade que sempre despertava reações ambivalentes dentro das classes dominantes da Amazônia (WEINSTEIN, 2002, p.268).

Se ampliarmos a proposta da autora de pensar conceitualmente o ciclo da borracha na Amazônia através da ideia de "relações de produção" e incluirmos aí a possibilidade de pensar projetos em transformação, é preciso então situar os fluxos agregados de capitais entre nações como forma de sofisticação da borracha no mercado global e os sentidos que a relação com a terra na Amazônia contemporaneamente. As negociações condensadas nesse momento e seus efeitos sobre as relações entre trabalhadores e capitalistas por um lado, e entre diferentes segmentos no interior da própria sociedade, por outro, assumiram formas e foram tensionadas pela recessão e pelo recrudescimento da demanda por matéria prima no cenário nacional e também pela conformação de formas politizadas de organização de grupos subalternizados, a exemplo de populações indígenas e extratores com o processo de redemocratização no último quarto do século XX.

Essas transformações devem ser pensadas a partir da possibilidade de uma continuidade entre relações de produção, relações entre segmentos portadores de diferentes privilégios e possibilidades de negociação, e por fim, entre dispositivos semânticos para expressar a relação com a terra.

\section{QUESTÕES FINAIS}

Pensar a produção de um espaço é pensar a articulação entre diferentes cadeias de eventos em transformação. A Amazônia é um espaço potencialmente complexo para se observar algumas dessas questões tendo em vista o volume de sujeitos envolvidos na construção e experimentação desses eventos em conexão. Todavia, é possível pensar a implicação desse arsenal de regimes de significados, atores e modos de existência a partir de algumas questões que podem sugerir os valores históricos dessa breve reflexão e seus efeitos para outras temporalidades. Na arena dessas cadeias de transformação que se desenvolvem no e produzem o cenário amazônico ao longo do processo histórico, como poderíamos pensar as relações entre comunidades 
extratoras tituladas com a posse da terra após década de expropriação de sentidos, práticas e recursos? Como pensar o lugar da borracha numa economia contemporânea em reservas extrativistas que remete por oposição ao passado das relações de violência e violação de direitos? Como compreender as relações entre sociedade, trabalho e terra sem ignorar as conexões entre experiências de mercado como a borracha, os créditos de carbono reconhecendo alguma dignidade aos povos da floresta e à própria floresta como um vivente e portador de uma narrativa sobre as sociedades? Quem são os novos caboclos e extratores dessas economias do futuro possível?

Essas questões não podem ser respondidas sem recorrer a uma reflexividade que articule diferentes questões e perspectivas em conflito, mas talvez elas atualizem as particularidades e tensões da experiência social de construção de uma Amazônia para os nossos tempos.

\section{REFERÊNCIAS}

BUTLER, Judith. "Vida Precária" vol.1, n.1. In. Contemporânea: revista de sociologia da UFSCAR. São Carlos, 2011. P.13-33.

FREYRE, Gilberto. Casa Grande e Senzala. São Paulo: Globo, 2011 [1993].

GOMES, Márcio. "Amazônia e modernidade". In: Estudos Avançados, vol.16, n.45. São Paulo, 2002, p.31-36.

GOMES, Mércio Pereira. Os índios e Brasil. Petrópolis: Vozes, 1991,

LACERDA, Franciane Gama; VIEIRA, Elias Regina Corrêa; '“O celeiro da Amazônia': agricultura e natureza no Pará na virada do século XIX para o XX. In: Topoi, vol.16, n.30. Rio de Janeiro. 2015. p.157-181.

PANTOJA, Mariana Ciavata. Os Milton: cem anos de história no seringal. Rio Branco: EdUAC, 2008. 
WEINSTEIN, Barbara. "Experiência de pesquisa em uma região periférica: a Amazônia". In: História, Ciências, Saúde - Manguinhos. Vol. 9, n.2. Rio de Janeiro, 2002. p.261-272.

Enviado: Janeiro, 2020.

Aprovado: Maio, 2020. 